\title{
COMPARATIVE STATE EMPLOYMENT GROWTH: AN EXPLORATORY INVESTIGATION
}

\author{
Roger F. Riefler
}

\begin{abstract}
This paper uses the Mead/Ramsay version of shift/share analysis to investigate the comparative employment performance $(80 \mathrm{~s}$ vs. $70 \mathrm{~s}$ ) of the 50 states and D.C. State performance is ranked and compared with various measures of business climate, labor costs and trade sensitivity. The results are disappointing. More interesting results are derived when state policy measures are contrasted to improvement in state comparative advantage. These results, plus the geographic clustering of states improving their performance, suggest further research is warranted.
\end{abstract}

\section{INTRODUCTION}

State and local government efforts to promote economic growth have a long history in this country, dating at least from the construction of the Erie Canal in the early 19th. century. Such initiatives receded in importance during the laissez faire era of the latter half of that century, but the inter-war period in this century witnessed, especially in the South, a renewed interest in indigenous measures designed to foster local development. It is the decade of the 1980s, however, that seems to mark the (re)birth of what has been called the entrepreneurial state. ${ }^{1}$ Whether due to a cutback in federal development spending, the impact of the 1981/82 recession, a renewed faith in the efficacy of small business as a growth vehicle, an interest in what might be labeled an industrial policy, or a combination of these factors, states and local communities have become more active in attempting to influence their growth trajectory. This trend certainly appears to have carried over into the 1990s.

While few would debate the growing number of state and local programs aimed at promoting growth, there is less agreement on the effectiveness of these policies. Attempts to gauge the impact of state and local development efforts fall into two broad categories: micro and macro approaches. ${ }^{2}$ Micro studies, as exemplified by benefit/cost studies of the location of auto assembly plants or sports facilities and franchises, are case specific. Macro studies, on the other hand, tend to focus on the correlation of state and local (developmental) government expenditures and/or taxes with observed economic growth. Certainly the growing importance of state and local development programs underscores the significance, timeliness and complementary nature of these approaches for policy evaluation.

*Professor of Economics, University of Nebraska-Lincoln. 
Unfortunately, the jury is still out on the overall efficacy of state and local government development efforts.

The purpose of this paper is not to reach a definitive judgment on this crucial issue. The objectives, rather, while germane to the issue, are more modest. First, we attempt to document whether, in comparing state-level employment growth in the 1980s with that in the 1970s, there has been a shift in the pattern of competitiveness or comparative advantage. Has the blossoming of the entrepreneurial state been associated with a significant shift in the pattern of state level competitive employment growth? Or, does employment growth in the 80 s represent a continuation of past trends? The contribution of this part of the paper is a more precise definition of a state's differential competitiveness. Two indices are developed to measure the improvement/deterioration in comparative advantage as a location for economic growth. These summary measures clearly place our study in the macro tradition referred to above. While a finding of shifting patterns in state competitiveness does not directly (or indirectly) imply a causative role for development policy, such a change may be attributable to differential policies. Certainly a finding of employment growth "as usual" would lead one to question policy effectiveness.

The second objective of the paper is to investigate, in a preliminary fashion, possible determinants of differential state employment growth patterns. Summary measures of state level "business climate" are correlated with differential growth patterns to explore possible direct and indirect avenues of policy impact. The correlation of specific policy variables, such as the stringency of environmental regulation, as well as variables that may be indirectly amenable to policy manipulation-for instance, labor costs-with differential performance will be examined. The analysis is exploratory in the sense that simple (rank) correlations rather than multiple, stochastic techniques will be utilized. Although many of our potential explanatory variables, such as various indices of business climate and environmental stringency, are themselves (weighted) clusters of multiple component indices, they will be treated as single-dimension indicators of the competitive environment. Hopefully, our results, while not answering the crucial question of the direct and indirect effectiveness of state level economic development policies, will indicate fruitful avenues for research into this challenging issue.

The organization of the paper is as follows: The following section presents the basic model used to compare state level performance in the 1980s versus the 1970s. This section also presents the results of applying this methodology to total nonagricultural employment growth and its manufacturing component. Employment is used as the measure of development (although the method could be applied to income change) since it is the most commonly utilized growth indicator at the regional level as well as a frequent gauge of policy impact. The following part 
of the paper presents the preliminary investigation of the correlates of differential performance. Emphasis will be placed on possible "causes," direct and indirect, subject to state-level policy manipulation. A concluding section of the paper summarizes our results and, more importantly, suggests further directions for research.

\section{STATE DIFFERENTIAL PERFORMANCE}

The model applied to identify what will be called the differential state competitiveness measure, abbreviated as DSCM, is the Mead and Ramsay (1982), or MR, variant of shift/share analysis. Mead and Ramsay applied this model to the differential performance of the Massachusetts economy during the 1973-1975 and 1979-1980 recessions. Riefler (1986 and 1991) also applied this model to a single state in analyzing the growth performance of Nebraska in the 1980s versus the 1970s. This paper extends the model to all 50 states and the District of Columbia but utilizes growth periods consistent with Riefler (1991).

The MR approach allows one to compare two non-continuous time periods by adjusting for changes in industry structure with which a region enters the two growth (or decline) episodes. The model is summarized by equation (1):

$d C h E=\left[\left(E_{1}-E_{0}\right)\left(N_{0}+I_{0}+R_{0}\right)\right]+\left[E_{0}\left(\left(N_{1}-N_{0}\right)+\left(I_{1}-I_{0}\right)+\left(R_{1}-R_{0}\right)\right)\right]$

where $\mathrm{dChE}=$ the differential change in state employment growth in the 1980 s versus the 1970 s

\begin{tabular}{|c|c|c|}
\hline$\left(E_{1}\right)$ & & $\begin{array}{l}\text { dustries, indicating state employment } \\
\text { of the } 1970 \text { s (1980s) period of growth }\end{array}$ \\
\hline$\left(\mathrm{N}_{1}\right)$ & & $\begin{array}{l}\text { over i industries, of the net shift effect in the } \\
980 \text { s) growth period }\end{array}$ \\
\hline $\mathrm{I}_{0}\left(\mathrm{I}_{1}\right)$ & & $\begin{array}{l}\text { ndustries, of the industrial mix effect in } \\
\text { s) }\end{array}$ \\
\hline (F & & $\begin{array}{l}\text { a vector over i industries, of the regional competitive } \\
\text { effect for the } 1970 \text { s (1980s) }\end{array}$ \\
\hline
\end{tabular}

The first (bracketed) term on the right-hand side (RHS) of equation (1) measures, for each state, the differential change in employment, 1980s versus 1970s, due to changes in the employment base with which the region entered the two growth periods. Since the net shift $(\mathrm{N})$, industry mix (I) and regional effect (R) are kept constant at their 1970s level, this term captures the difference in 
growth due to changes in a state's industrial base between the March $1975\left(\mathrm{E}_{0}\right)$ and February $1984\left(\mathrm{E}_{1}\right)$ initiation dates of our growth episodes. While adjustment for changes in the employment base between the two decades is necessary for comparing relative performance, this component of the total differential change in employment does not relate to performance within each decade. For that reason it does not appear in Tables 1 and 2 below and is not used in assessing comparative performance in this paper.

For similar reasons, the first and second elements in the second bracketed term of the RHS of equation (1) are not the focus of this study. The first of these $E_{0}\left(N_{1}-N_{0}\right)$ measures the difference ( 80 s versus 70 s) in a state's performance attributable to the characteristics of the overall national expansion in the two decades. It is therefore analogous to the net shift effect of traditional shift/share analysis. The second, $\mathrm{E}_{0}\left(\mathrm{I}_{1}-\mathrm{I}_{0}\right)$, reflects differences in the national distribution of growth industries. A positive value for this effect, for instance, would indicate a relative gain due to the industrial pattern of the 1980s growth at the national level. Computationally, it is similar to the industry mix effect of traditional shift/share.

It is the third element of the second bracketed term, $E_{0}\left(R_{1}-R_{0}\right)$, which is of interest to this study. This term corresponds to the (base-adjusted) regional or competitive effect of traditional shift/share analysis. As in the case of shift/share analysis it is calculated for each industry in each of two time periods. It may be algebraically summed to obtain an overall index of (differential) regional competitiveness over the two time periods. A positive value for $E_{0}\left(R_{1}-R_{0}\right)$, the differential state competitiveness measure, or DSCM, indicates an improvement in a state's competitive position in the 1980 s $\left(R_{1}\right)$ versus the 1970 s $\left(R_{0}\right){ }^{3}$ A negative value indicates a decrease in a state's comparative advantage. This is the element of differential performance we wish to investigate and, ideally, at least partially explain. ${ }^{4}$

The model given by equation (1) was applied to (monthly) employment data, by state, for the periods March 1975 to January 1980 (labeled the 1970s) and February 1984 to December 1989 (the 1980s). The former time period represents the expansionary period of 58 months originating at the NBER benchmark nadir of the 73/74 recession. The latter period represents a 71-month period of growth originating 14 months after the November, 1982 trough of the $81 / 82$ recession. ${ }^{5}$ December 1989 was used as a terminal date for this period to avoid the effects of the $90 / 91$ recession.

The basic source for monthly employment data was the Bureau of Labor Statistics, U.S. Department of Labor (1989 and 1991). To insure comparability of results among the states, the MR technique was applied at a relatively high level of industrial aggregation. The sectoring plan utilized included (1) manufacturing, 
TABLE 1

Change in State Competitiveness

1980 s vs. 1970 s TOTAL EMPLOYMENT

\begin{tabular}{|c|c|c|}
\hline STATE & $\begin{array}{c}E_{0}\left(R_{1}-R_{0}\right) \\
\text { (In } 1000 \text { s of jobs) }\end{array}$ & $\begin{array}{c}\text { Column } 1 \text { as a \% of } \\
\text { Dec. } 1989 \text { Total } \\
\text { Employment }\end{array}$ \\
\hline Delaware & +42.442 & $+12.23 \%$ \\
\hline Indiana & +236.414 & +9.40 \\
\hline Ohio & +371.819 & +7.57 \\
\hline New York & +526.626 & +6.28 \\
\hline Kentucky & +91.199 & +6.24 \\
\hline Hawaii & +30.117 & +5.81 \\
\hline Pennsylvania & +288.723 & +5.59 \\
\hline Maryland & +117.211 & +5.38 \\
\hline Michigan & +206.524 & +5.22 \\
\hline Maine & +28.606 & +5.19 \\
\hline District of Columbia & +35.590 & +5.13 \\
\hline Tennessee & +102.064 & +4.68 \\
\hline Virginia & +125.738 & +4.32 \\
\hline Illinois & +171.894 & +3.29 \\
\hline Wisconsin & +62.588 & +2.77 \\
\hline Iowa & +33.613 & +2.75 \\
\hline New Jersey & +87.933 & +2.34 \\
\hline Florida & +123.395 & +2.27 \\
\hline Missouri & +51.995 & +2.23 \\
\hline North Carolina & +68.178 & +2.18 \\
\hline Nebraska & +15.216 & +2.12 \\
\hline Georgia & +55.493 & +1.84 \\
\hline South Carolina & +24.661 & +1.61 \\
\hline Rhode Island & +1.885 & +0.41 \\
\hline Vermont & +0.549 & +0.21 \\
\hline Minnesota & -0.557 & -0.03 \\
\hline South Dakota & -0.625 & -0.23 \\
\hline Washington & -11.294 & -0.54 \\
\hline Alabama & -10.817 & -0.67 \\
\hline Connecticut & -15.252 & -0.90 \\
\hline Arkansas & -9.627 & -1.06 \\
\hline Massachusetts & -40.831 & -1.30 \\
\hline West Virginia & -8.314 & -1.34 \\
\hline Alaska & -3.614 & -1.63 \\
\hline Oregon & -20.459 & -1.66 \\
\hline California & -256.614 & -2.00 \\
\hline Utah & -15.508 & -2.17 \\
\hline Idaho & -11.725 & -3.08 \\
\hline Nevada. & -22.013 & -3.63 \\
\hline Mississippi & -34.082 & -3.64 \\
\hline Arizona & -56.535 & -3.75 \\
\hline Kansas & -45.785 & -4.21 \\
\hline New Hampshire & -26.164 & -5.00 \\
\hline New Mexico & -35.364 & -6.20 \\
\hline Montana & -25.603 & -8.70 \\
\hline Colorado & -181.702 & -12.17 \\
\hline North Dakota & -32.260 & -12.32 \\
\hline Texas & -863.589 & -12.51 \\
\hline Oklahoma & -206.783 & -17.69 \\
\hline Louisiana & -320.794 & -20.98 \\
\hline Wyoming & -53.751 & -27.74 \\
\hline
\end{tabular}


TABLE 2

Change In State Competitiveness

1980s vs. 1970 s

MANUFACTURING EMPLOYMENT

\begin{tabular}{|c|c|c|}
\hline STATE & $\begin{array}{c}E_{0}\left(R_{1}-R_{0}\right) \\
\text { (In } 1000 \text { s of jobs) }\end{array}$ & $\begin{array}{c}\text { Column } 1 \text { as a \% of } \\
\text { Dec. } 1989 \mathrm{Mfg} . \\
\text { Employment }\end{array}$ \\
\hline District of Columbia & +5.249 & $+32.60 \%$ \\
\hline Alaska & +3.556 & +30.65 \\
\hline North Dakota & +3.919 & +23.19 \\
\hline West Virginia & +14.452 & +16.54 \\
\hline Indiana & +100.302 & +15.72 \\
\hline Iowa & +32.374 & +13.74 \\
\hline Delaware & +9.950 & +13.65 \\
\hline Washington & +42.524 & +11.61 \\
\hline Ohio & +128.905 & +11.49 \\
\hline Kentucky & $\begin{array}{l}+32.607 \\
\end{array}$ & +11.41 \\
\hline Illinois & +110.123 & +11.22 \\
\hline Nebraska & +8.026 & +8.35 \\
\hline Pennsylvania & +83.035 & +7.98 \\
\hline Hawaii & +1.601 & +7.70 \\
\hline Maryland & +15.761 & +7.55 \\
\hline Wisconsin & +39.516 & +7.15 \\
\hline Idaho & +3.733 & +5.94 \\
\hline Mississippi & +13.424 & +5.54 \\
\hline Tennessee & +27.490 & +5.24 \\
\hline New Mexico & +2.072 & +4.88 \\
\hline Michigan & +33.915 & +3.53 \\
\hline Missouri & +13.229 & +3.01 \\
\hline Wyoming & +0.256 & +2.84 \\
\hline Minnesota & +6.663 & +1.68 \\
\hline New York & +19.798 & +1.68 \\
\hline Virginia & +6.699 & +1.56 \\
\hline Alabama & +5.838 & +1.53 \\
\hline New Jersey & +1.922 & +0.30 \\
\hline Oregon & -2.277 & -1.05 \\
\hline Kansas & -2.629 & -1.42 \\
\hline North Carolina & -12.321 & -1.42 \\
\hline Arkansas & -3.506 & -1.53 \\
\hline Utah & -1.953 & -1.88 \\
\hline Montana & -0.550 & -2.44 \\
\hline Georgia & -15.010 & -2.63 \\
\hline Louisiana & -6.827 & -3.89 \\
\hline South Carolina & -20.176 & -5.13 \\
\hline California & -118.872 & -5.53 \\
\hline Florida & -33.493 & -6.11 \\
\hline Nevada & -2.390 & -9.30 \\
\hline Colorado & -21.133 & -10.85 \\
\hline South Dakota & -3.640 & -11.63 \\
\hline Connecticut & -43.672 & -12.21 \\
\hline Maine & -13.360 & -12.58 \\
\hline Arizona & -24.837 & -13.18 \\
\hline Texas & -136.975 & -14.13 \\
\hline Rhode Island & -16.698 & -15.56 \\
\hline Vermont & -7.326 & -15.59 \\
\hline Oklahoma & -26.940 & -16.33 \\
\hline Massachusetts & -111.670 & -20.21 \\
\hline New Hampshire & -30.585 & -27.36 \\
\hline
\end{tabular}


(2) mining, (3) construction, (4) transportation, communication, and utilities, (5) trade, (6) finance, insurance and real estate, (7) services, and (8) government.

Table 1 presents the total differential competitive effect, or DSCM, summed over all eight sectors for each state. The first column of data contains the absolute value of the DSCM. As indicated above, a positive entry in this column represents an improvement in the state's competitive position as a location for employment growth in the 1980s (versus the 1970s). Thus Indiana recorded 236,414 more jobs in the 1980s expansion than during the 1970s after adjusting for the differential rate of national expansion, the state's industrial mix in the two periods, and the change in industrial composition between the two growth episodes. Conversely a negative value indicates a diminution in comparative advantage between the two periods. The final column in Table 1 adjusts the DSCM for the relative size of the state's economy by dividing the entry in column 1 by total state employment in December 1989. Entries in Table 1 are collated to range from the largest favorable relative DSCM (i.e., Delaware, +12.23 percent) to the least favorable (i.e., Wyoming, -27.74 percent). To facilitate an analysis of the spatial pattern of DSCMs, Figure 1, Panel A presents a map of the 48 contiguous states, indicating those recording an improvement in competitive position.

Table 2 and Figure 1, Panel B, present a similar tabulation and geographic distribution, respectively, for the manufacturing component of the total differential competitive effect. Manufacturing is important since, of the eight sectors analyzed, it is the most likely to consistently serve interregional, national and/or export markets. As such it is most likely to be affected by the full set of market forces at work in the economy as well as being a part of the export base of an individual state's economy.

To oversimplify the pattern somewhat, those states showing consistent improvement in their competitive position are found in a broad swath extending from the Middle Atlantic states to Iowa, Nebraska and Missouri. Most states composing the "Rust Belt" are found in this group of states. Gulf Coast states, as well as the Southwest and Mountain regions (with the exception of New Mexico, Wyoming and Idaho), and California and Oregon exhibit declines in their total and manufacturing competitive performance. Other areas exhibit sign reversals when comparing total and manufacturing DSCMs. ${ }^{6}$ Especially noteworthy is the change in the Southeast from positive total to negative manufacturing DSCM's. The high incidence of energy-producing areas in the bottom ten with respect to total DSCM's is not surprising, given the boom and bust experiences of these industries during the last two decades.

The data in Tables 1 and 2 yield some insights into the transition of the U.S. economy from ruralization in the 1970s to (a return to) urbanization in the 1980s. A recent article by R. D. Norton (1991) calculated the percent of each state's 


\section{FIGURE 1}

States Recording an Improvement in Competitiveness 1980 s vs. 1970 s

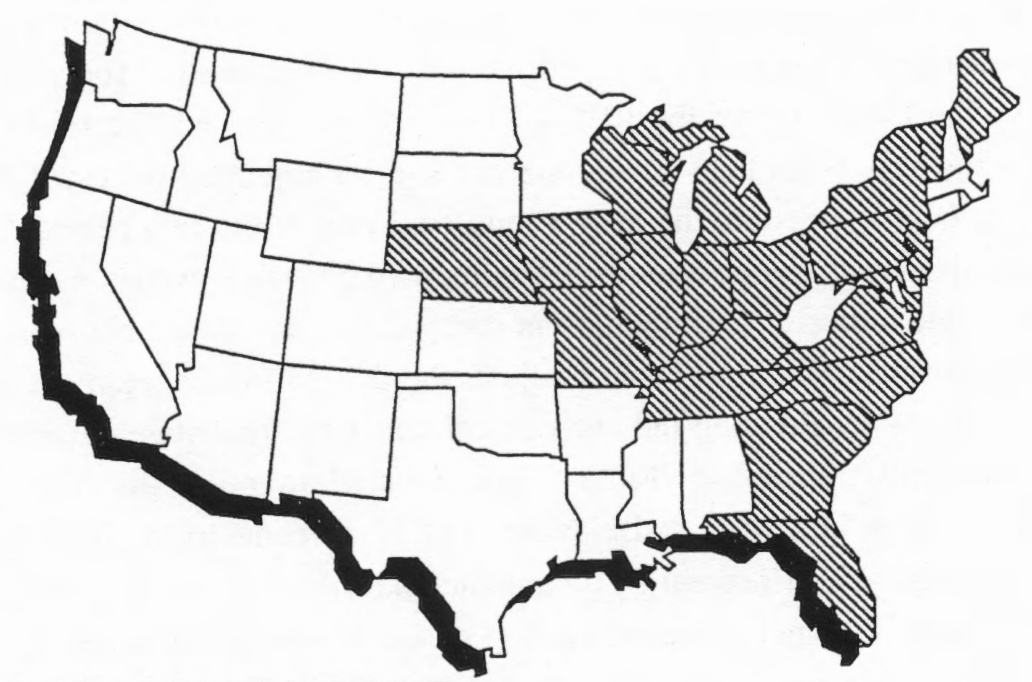

PANEL A: TOTAL EMPLOYMENT

(Shaded States Recorded Positive DSCM's-See Table 1)

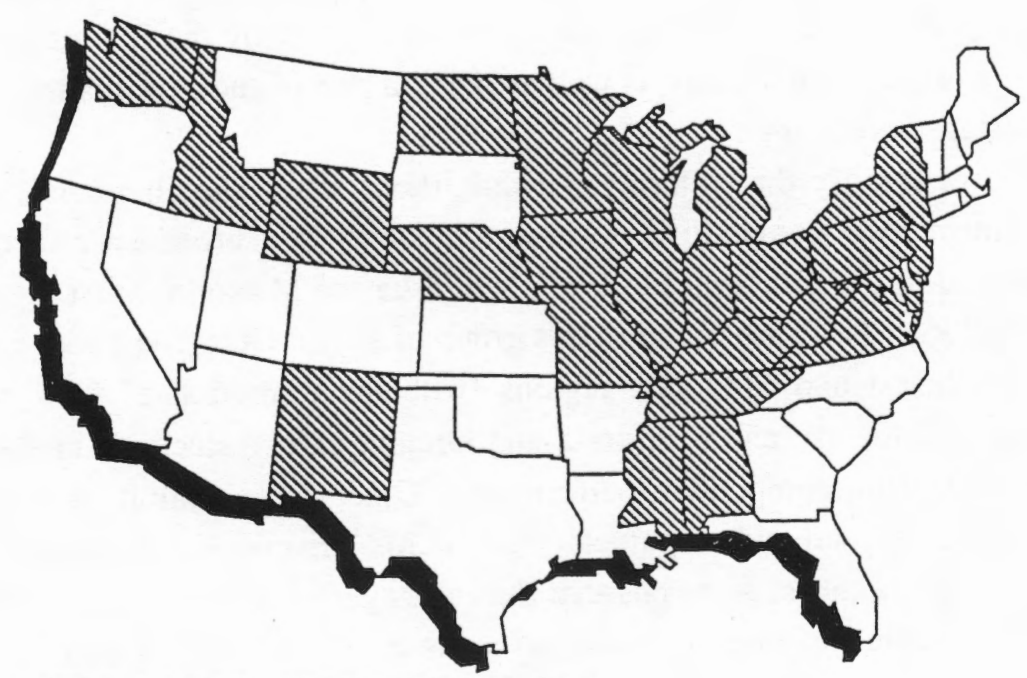

PANEL B: MANUFACTURNG EMPLOYMENT

(Shaded States Recorded Positive DSCM's-See Table 2) 
population living outside of metropolitan areas. If we rank each state by this indicator and compare the rankings with those reported in Table 1, we find a significant (at the 90 percent, but not the 95 percent confidence interval) negative Spearman rank correlation coefficient $(R=-0.268)$ between the percent of population non-metro and improvement in state competitiveness. For the manufacturing DSCMs of Table 2, the correlation was positive (+0.161) but insignificant. It therefore appears that it was location patterns within the tertiary, or more correctly, non-manufacturing, sectors that explained the return to historic patterns of urbanization in the 1980s. The higher the percent of a state's population located in metropolitan areas, the greater the improvement in non-manufacturing DSCMs.

\section{EXPLAINING THE DIFFERENTIAL COMPETITIVE EFFECTS}

Although the geographic distribution of differential competitive effects or DSCM's recorded in Tables 1 and 2 (and Figure 1) is both interesting and suggestive of some significant degree of spatial continuity or contiguity in underlying causal factors, the challenge is to isolate the factor(s) responsible for the pattern. Location theory suggests a myriad of factors, ranging from market accessibility to factor costs, that might be responsible for the relative differential improvement (or deterioration) in competitive effects between the 1970 s and 1980 s. $^{7}$ Given this variety of factors that could be considered candidates for analysis, as well as the probability that a combination of elements is likely at work, it was decided to investigate first the relationship between the empirical results reported in Tables 1 and 2 and a measure of the overall "business climate" for each of the fifty states. ${ }^{8}$

As recently pointed out by Charles L. Skoro $(1988$, p. 139), ". . the usefulness of the business climate concept depends on the existence of a set of indicators that are measurable, that have substantial effects on business outcomes, and that are truly generic-they influence business activity in a more or less uniform manner regardless of industry, region or time period" (emphasis in original). Unfortunately identifying and quantifying the dimensions of business climate has been a daunting experience. The term, therefore, remains a challenging but nebulous concept. The tack taken by this paper is to utilize existing attempts to define business climate rather than to generate our own. Investigating the correlation between these indices and state differential competitive performance over the past decade will, hopefully, both illuminate the factors causing the observed behavior and, more importantly, suggest further avenues for future investigation. ${ }^{9}$

Currently the three most widely cited business climate studies are those released by Grant Thornton, Inc. Magazine, and the Corporation for Enterprise 
Development (CED). The annual Grant Thornton studies rank the contiguous 48 states on a combination of 22 factors pertaining to (1) state and local government fiscal policies, (2) state-regulated employment costs, (3) labor costs, (4) availability/productivity of labor, and (5) miscellaneous factors. ${ }^{10}$ The annual studies rely on a survey of state manufacturers' associations to determine the weights used to compute the overall index representing a state's business climate. As pointed out by Skoro (1988, pp. 140-141), state and local government policy and entailing factors controllable by government "looms quite large" in the GrantThornton weighing scheme.

The 1985 Grant-Thornton ranking of states was chosen to compare with the recorded differential competitive effects of Tables 1 and 2 . These tables were adjusted by deleting Hawaii, Alaska and the District of Columbia in order to be comparable with the Grant-Thornton calculations. 1985 was chosen rather than 1984 (e.g., the first year of our "1980s") so as to capture "announcement effects" of policy changes on 1984-1989 economic performance. It was anticipated that comparison of business climate rankings to Table 2's relative DSCMs for manufacturing would be more congruent, given Grant-Thornton's attempt to isolate manufacturing climate through both its weighing scheme and choice of factors.

Unfortunately, results were disappointing. The Spearman rank correlation coefficient between Grant-Thornton and total DSCMs was -0.214 . While the negative coefficient was counterintuitive, indicating that states with better business climate showed deterioration in competitive performance, the coefficient was not significantly different from zero at the 90 percent confidence interval. The correlation coefficient with the relative differential competitiveness of manufacturing was -0.193 (also not significant).

The 1985 ranking of state business climate published by Inc. Magazine utilized measures of availability of capital, direct state aid to business (a more pro-active measure of state economic development policy than the government measures in Grant-Thornton), labor costs and quality, and measures of recent business activity. Specific state policies to aid small business accounted for 25 percent of the overall index. ${ }^{11}$ States with strong, aggressive financial sectors also tend to rank high in the Inc. business climate measure.

The (Spearman rank) correlation coefficient between 1985 Inc. Magazine's ranking of 50 state business climates and the results reported in Tables 1 and 2 was, again, disappointing. Although the correlation coefficient between 1985 business climate and total differential competitiveness was positive $(+0.068)$ it was not significantly different from zero. The correlation with the relative DSCMs for manufacturing was significantly different from zero at the 95 percent confidence interval, but the negative coefficient $(-0.304)$ indicated that a better 
climate inhibited increased competitiveness. This result is especially surprising since the Inc. measure of business climate included 1982-1984 employment growth in a state as one of five factors determining "business activity" (the latter category having a weight of 20 percent in the overall index).

The final study of overall business climate published by the Corporation for Enterprise Development (1987) is more complex. The 1985 report by this entity provided four different measures of business climate. ${ }^{12}$ In addition Skoro (1988) computed a composite index by combining the four published indices. The four individual indices are the performance index, the business vitality index, the capacity index, and the policy index.

The performance index supplements measures of income and employment growth with considerations of job quality, the income distribution and three proxies taken to measure quality of life. The business vitality index attempts to capture the competitiveness of existing businesses and the entrepreneurial activity in the state. The capacity index aims at measuring the potential for future growth by combining indices of human, financial and infrastructure resource availabilities with an amenities index. Finally, the policies index is based on a compilation of the number of state programs enacted in areas such as mobilizing capital, enhancing technology and human resources and helping distressed communities as well as some broader policy measures. Skoro computed the composite index by simply averaging a state's ranking on the four component indices. ${ }^{13}$

Table 3 summarizes the resulting Spearman rank correlation tests between Tables 1 and 2 rankings of the relative DSCMs for total and manufacturing employment and the five CED indices (including Skoro's composite index) of business climate.

\section{TABLE 3}

Rank Correlations: DSCM's versus

CED Business Climate Rankings, 1985

\begin{tabular}{lcc} 
INDEX & TOTAL (RELATIVE) DSCM & MFG. (RELATIVE) DSCM \\
\hline Composite Index & +0.144 & -0.136 \\
Performance Index & $+0.247^{*}$ & -0.133 \\
Capacity Index & +0.031 & -0.136 \\
Vitality Index & $-0.295^{* *}$ & $-0.283 * *$ \\
Policy Index & +0.148 & $+0.545^{* * *}$ \\
\hline
\end{tabular}

- Significant at the $90 \%$ interval.

** Significant at the $95 \%$ interval.

*** Significant at the $99 \%$ interval.

Skoro's composite index and the CED's capacity index show no significant correlation with the relative differential competitive effects. Not surprisingly the 
performance index, with its 40 percent weight on employment and income growth, exhibits a positive, significant correlation with increased total competitiveness. Note, however, the negative, but insignificant, correlation of this index with the competitive differential for manufacturing. It is tempting to attribute this negative relationship to the inclusion in the performance index (positively) of average hourly earnings of production workers in manufacturing in 1985. This measure is only one of four contained in the "job quality" component (weight 20 percent) of the overall performance index. A more direct test of the hourly manufacturing wage/manufacturing DSCM relationship appears warranted and will be tested below.

More surprising are the negative and significant rank correlations between the business vitality index and changes in state total and manufacturing competitiveness. On the surface these relationships suggest that the more competitive a state's industrial structure (weight 50 percent) and the more entrepreneurial energy present (weight 50 percent) the poorer a state's performance in the 80 s versus the 70 s. Skoro tabulates the components of this index as: ${ }^{14}$

\section{COMPETITIVENESS: 1 . Export-related manufacturing as a percentage of state manufacturing, 1983}

2. New capital expenditures per production worker, 1984

3. Percent of business with Inc. Magazine 1982-1986 growth index over 20

4. Fortune 1000 headquarters per million residents

ENERGY: 1. Percent of business establishments founded after 1981 with 10 or more employees by 1986

2. Non-agricultural self-employed as a percent of labor force, 1980

3. Percent of female labor force owning businesses, 1982

4. Percent of minority labor force owning businesses, 1982

One might suspect that the "competitiveness" component of the business vitality index is misspecified. The strength of the negative correlation coefficient reported above clearly indicates that disaggregation of this index might be fruitful.

The final significant correlation coefficient in Table 3 is rather interesting. There is a high positive correlation between state and local government policies and a favorable shift in the state's competitive position as a location for manufacturing employment growth. On the other hand, there is no significant correlation 
between policy measures and an improvement in overall competitiveness. On the surface these results suggest that state and local development efforts have a positive impact on a state's comparative advantage, but these "efforts" continue their historical focus on the manufacturing sector (e.g., "smokestack chasing"). 15

The wage/DSCM relationship alluded to above in discussing the CED's performance index (and given the importance of labor costs in the total industrial cost structure) deserves a closer examination of the role of relative wages in determining state differential competitive performance. A recent article by George Treyz (1991) provides two measures of 1983 relative state wages. These can be ranked and correlated with the ranking contained in Tables 1 and 2 . The first indicator, which we shall call the unadjusted relative state wage, uses the proportion of total state employment in each industry to weight state versus United States wages by sector. The second measure, termed adjusted relative wages, compares the relative wage (state versus national average) that would be observed if each state had the U.S. industry mix. We rank each state's relative wages using both unadjusted and adjusted calculations and correlate with total and manufacturing DSCMs. The results are given in Table 4.

TABLE 4

Rank Correlations: DSCM'S versus

Treyz State Relative Wages

\begin{tabular}{lcc} 
RELATIVE WAGES & TOTAL (RELATIVE) DSCM & MFG. (RELATIVE) DSCM \\
\hline Unadjusted & +0.076 & +0.065 \\
Adjusted & +0.126 & -0.054 \\
\hline
\end{tabular}

Surprisingly, the positive coefficient for three of the four correlations reported in Table 4 would support the hypothesis that higher wage states exhibited the greatest improvement in competitive position in the 1980s. None of the reported correlation coefficients, however, is significantly different from zero at commonly accepted confidence intervals. ${ }^{16}$

The CED's policy index for 1985 excluded from consideration one important area of government policy-environmental controls. Certainly the decades of the 70 s and 80s have been a period of growing environmental awareness and increased environmental legislation and regulation. There remain significant variations, however, in the stringency of state environmental enactments. To what degree do the changes in state competitiveness in the 80 s (versus the 70s) reflect gradations in environmental policy? Do legislated environmental constraints and regulations help explain the change in state-level competitiveness captured in Tables 1 and 2? Does increased environmental stringency retard growth? 
A recent Ph.D. dissertation by David R. Aske (1992) developed an index of state-level environmental stringency. That index was based on ten environmental measures such as the extensiveness of state environmental policy legislation, the development of a new source review program, emission standards for hazardous wastes, a noncompliance penalty program, opacity standards, various permit programs and per capita expenditures on air and water pollution control programs. ${ }^{17}$ Weights for combining the factors into an overall index were based on a survey of state economic development and environmental protection offices. ${ }^{18}$ The index was constructed to measure environmental stringency as of approximately $1980 .^{19}$

After constructing his stringency index, Aske correlated it with observed state-level manufacturing employment growth. Surprisingly, he found a positive correlation between stringency and employment growth. ${ }^{20}$ Unfortunately, his calculations did not adjust observed state-level growth for "share" and industry mix effects, nor did it correlate environmental stringency with differential state performance. Correlating Aske's environmental stringency index, developed for the early $80 \mathrm{~s}$, with the change in a state's comparative advantage as a location for employment growth during the 1980 s versus the 1970 s, appears a more direct test of the growth/environmental concern nexus.

A Spearman rank correlation between Table 1's change in total state competitiveness (1980s versus 1970s) and Aske's index yields a coefficient of +0.365 . This is significantly different from zero at the 95 percent confidence interval. ${ }^{21}$ The positive result, consistent with Aske's findings for manufacturing, indicates that the more stringent a state's environmental policy, the larger the favorable change in its competitive position as a location for employment growth. Clearly, this finding runs counter to the claim that environmental legislation, at least as implemented through 1980, inhibits growth.

A similar correlation using the ranking of states based on improvements in a state's comparative advantage as a location for manufacturing (i.e., Table 2) yields a coefficient of +0.167 . This is not significant at the 90 percent confidence interval. ${ }^{22}$ The positive coefficient certainly would lead one to question the more stringency/less growth hypothesis. When combined with the previous result, it suggests that environmental stringency has a neutral impact on a state's comparative advantage overall as a location for manufacturing. For non-manufacturing industries, it appears that environmental stringency creates an amenity highly correlated with increased competitiveness in the 1980s.

A final attempt to explain changes in state competitiveness in the 80 s versus the 70s entailed a comparison of state performance with its sensitivity to international trade. W. M. Cox and J. K. Hill (1988) computed a state sensitivity index to fluctuations in the terms of trade. It was hypothesized that states most sensitive to 
improvements in the terms of trade (stimulating export demand for state products and decreasing import competition) would exhibit the largest improvement in comparative advantage. The ranked Cox-Hill index, unfortunately, showed no significant correlation with either total DSCMs $(R=+0.078)$ or manufacturing $\operatorname{DSCMs}(-0.210){ }^{23}$

\section{CONCLUSIONS AND DIRECTIONS FOR FURTHER RESEARCH}

In the introduction to this paper, two issues were raised. The first was whether there had been a shift in the pattern of state competitiveness when comparing the 1980s with the 1970s. Utilizing the Mead/Ramsay model to adjust for national and industry mix effects as well as changes in the industrial base between the two decades' growth episodes, our results, summarized in Tables 1 and 2 , showed significant shifts in state competitiveness. For both total and manufacturing employment, the geographic regularity exhibited by changes in comparative advantage was suggestive of a common set of spatial factors explaining differential performance.

The second issue raised in the introduction concerned the overall efficacy of state and local development efforts. States have made serious efforts to improve the health of their economies during the last several years. Considering the full panoply of direct (i.e., tax concessions, etc.) and indirect (i.e., infrastructure improvements, etc.) available to policy makers, not surprisingly, not all states have pursued the same course. Thus, unless all the efforts have been a waste of time (a distinct possibility), one should find that some states have been more successful than others in improving their economies. Our results, utilizing the CED's policy index, suggest that "traditional" economic development initiatives of the entrepreneurial state as captured by that index may have had a significant impact on improving a state's comparative advantage as a location for manufacturing activities in the 1980s. No evidence was found supporting the effect of these development efforts on non-manufacturing employment growth. Further, measures of overall state "business climate" failed to explain the observed shifts in state-level competitiveness. To the extent indirect state policies aim at the improvement of the business environment, these results suggest that either available measures are unsuccessful in capturing this nebulous concept or that such initiatives have not (yet?) had the desired impact on competitiveness.

In the area of environmental regulation our results suggest that increased stringency at the state level has no impact on overall change in competitiveness as a location for manufacturing growth. This lack of correlation is significant, given the alleged negative impact of environmental legislation on such growth. With regard to total non-manufacturing, our results indicate that increased environmen- 
tal policy stringency is consistent with improved competitiveness. Given that the environment is more likely to be viewed as an amenity rather than as an input by establishments outside the manufacturing sector, this result should not be all that surprising.

Obviously, the findings reported in this paper suggest that additional testing, especially at a more (industrially) disaggregated level, may be fruitful. Further, utilization of multivariate stochastic techniques, as opposed to the simple ordinal correlation methods emphasized by this paper, may provide additional insights. But just as clearly, the exploratory results reported here and the importance of the issues involved warrant such endeavors.

\section{ENDNOTES}

1. See Eisinger (1988) and Fosler (1988) for a documentation of renewed and expanded development efforts.

2. See Bartik (1991) for a useful compendium and evaluation of this large and rapidly growing literature.

3. Note that this improvement could be a reduction in competitive disadvantage or an increase in competitive advantage between the two time periods.

4. As in the case of shift/share analysis, if the sum of $E_{0}\left(I_{1}-I_{0}\right)$ and $E_{0}\left(R_{1}-\right.$ $\mathrm{R}_{0}$ ) were to equal zero, a state's growth performance would be similar to that recorded by the nation. The $E_{0}\left(I_{1}-I_{0}\right)$ captures the effect of differential industry mix on state performance, 1980 s versus 1970 s; $\mathrm{E}_{0}\left(R_{1}-R_{0}\right)$ captures the residual which we label, following in the shift/share tradition, the differential regional or competitive effect.

5. February 1984 was chosen as opposed to the NBER trough of November, 1982, for two reasons. First, several states, especially in the Farm Belt, did not begin their recovery till early 1984 . Second, cutbacks in federal economic development funding and policy lags at the state level made it likely that state and local economic development efforts (e.g., the "entrepreneurial state") could be better measured using the former date. See Riefler (undated), pp. $12-14$, and the references in endnotes 1 and 2.

6. A (Spearman rank) correlation coefficient between the rankings of total and manufacturing DSCMs in Tables 1 and 2 is +0.416 , which, while indicating a rather weak relationship, is significantly different from zero at the 99 percent confidence interval.

7. Note that the hypothesis of this paper states that relative DSCMs are influenced by the level of locational factors such as business climate, labor costs, trade sensitivity and environmental stringency. An alternative would be to test 
whether comparative state performance was influenced by changes in these factors. The information necessary to test these alternative hypotheses was not available. We therefore test only whether low labor cost (or trade-sensitive) states, for instance, showed the greatest improvement in competitiveness in the 80 s as opposed to whether states recording smaller increases in labor costs were so favored. With regard to business climate, we are implicitly assuming that in the 70 s either states did little in the area of economic development (which is unlikely) or that there was little difference between the states. R. Scott Fosler's (1988) and Peter K. Eisinger's (1988) books support the growing variety of state-level economic development efforts in the 80 s (vs. the 70s).

8. On the concept of business climate see Erickson (1987), Steinnes (1984) and Skoro (1988).

9. Since business climate indices combine various locational determinants in their construction it would be inappropriate to utilize them in combination with other, more traditional, locational determinants in a multivariate attempt to explain the DSCMs reported in Tables 1 and 2. Further, since the weights used in constructing the composite indices are largely subjective, it was decided to utilize rank (or ordinal) rather than stochastic (or cardinal) correlation analysis to test the explanatory power of these measures.

10. See Skoro (1988), p. 141, for a listing of all 22 factors and their weights in deriving the overall business climate index.

11. Skoro (1988), p. 144.

12. For a more recent version see CED (1990).

13. Skoro (1988), p. 148. For a more detailed presentation of the factors considered in the component indices see pp. $146-147$ of that article. For final rankings on each index see p. 149.

14. Skoro (1988), p. 146.

15. A perusal of the components of the policies index shows a variety of diverse programs included. While some, like "enhancing technology and business development," might focus on manufacturing, others (e.g., investing in human resources and helping distressed communities) have a wider appeal.

16. If we utilize Treyz (1991) original cardinal rankings and the actual relative improvement recorded in either Tables 1 and 2, column 2 (instead of a state's ordinal rank), this conclusion is unaltered.

17. Aske (1992), pp. 107 - 113.

18. Aske (1992), pp. $113-117$. See endnotes 7 and 9 for the rationale for utilizing rank correlation as opposed to stochastic techniques.

19. Aske (1992), p. 150.

20. Aske (1992), p. 150. 
21. The positive correlation is close to significant at the 99 percent confidence interval $(Z=2.51$ vs. a critical value of 2.58$)$.

22. $Z=1.14$ versus a critical value, at the 90 percent level, of 1.64 .

23. A correlation between the absolute or cardinal value of a state's CoxHill index and the actual relative total DSCMs, however, resulted in a statistically significant coefficient on the trade sensitivity index. E.g.:

Total DSCM $=-11.0367+0.1098$ Cox - Hill Index

$$
\mathrm{R}^{2}=0.1231
$$

where the absolute value of the " $t$ " statistic is in the parenthesis. This result would indicate that, other things equal, the more sensitive a state is to international trade, the greater the improvement in its competitiveness in the 80 s versus the 70 s. This would be consistent with the depreciation of the dollar in the 80s. However, when the manufacturing DSCMs are substituted for the total DSCMs, the coefficient is not significant. When combined with Treyz' (1991) labor cost variables neither trade sensitivity nor labor cost variables were significant at the 95 percent confidence interval.

\section{REFERENCES}

Aske, D.R. "Environmental Regulation and Industrial Location: Testing the Relationship Between State Environmental Regulations and Changes in State Manufacturing Employment". Unpublished Ph.D. dissertation. University of Nebraska, 1992.

Bartik, T.J. Who Benefits From State and Local Economic Development Policies? Kalamazoo, MI.: W.E. UpJohn Institute for Employment Research, 1991.

Corporation for Enterprise Development. Making the Grade: The Development Report Card for the States. Washington, DC: CED, 1987.

Corporation for Enterprise Development. The 1990 Development Report Card for the States. Washington, DC: CED, 1990.

Cox, W. M., and J.K. Hill. "Effect of the Lower Dollar and U.S. Manufacturing: Industry and State Comparisons". Economic Review. Dallas: Federal Reserve Bank of Dallas. pp. 1 - 9, 1988.

Eisinger, P.K. The Rise of the Entrepreneurial State. Madison, Wi: The University of Wisconsin Press, 1988.

Erickson, R.A. "Business Climate Studies: A Critical Evaluation". Economic Development Quarterly, v.1:62 - 71, 1987. 
Fosler, R.S. The New Economic Role of American States. New York: Oxford University Press, 1988.

Grant-Thornton Co. A Study of Business Climate for the Forty-Eight Contiguous States of America. Chicago: Grant-Thornton. Various Years.

Margolis, N. "Report Card on the States". Inc. Magazine. October issue, Various Years.

Mead, A.C., and G.A. Ramsay. "Analyzing Differential Response of a Region to Business Cycles". Growth and Change, v. 13:38 - 42, 1982.

Norton, R.D. "Regions, the Dollar, and Reindustrialization". Journal of Urban Economics, v. 29:70 - 80, 1991.

Riefler, R.F. "Indirect Evidence on the Effectiveness of State-Level Development Policy". Faculty Working Paper, University of Nebraska, undated.

Riefler, R.F. "Comparative Cyclic Behavior of a Regional Economy: Nebraska in the 70s and 80s". The Review of Regional Studies, v. 16:24 - 30, 1986.

Riefler, R.F. "An Assessment of Economic Development Policy: Nebraska in the 1980s". Regional Science Perspectives, v. 21:3 - 26, 1991.

Skoro, C.L. "Ranking of State Business Climates: An Evaluation of Their Usefulness in Forecasting". Economic Development Quarterly, v. 2:138 - 152, 1988.

Steinnes, D.N. "Business Climate, Tax Incentives, and Regional Economic Development". Growth and Change, v. 15: 38 - 47, 1984.

Treyz, G.I. "Causes of Changes in Wage Variation among States". Journal of Urban Economics, v. 29:50 - 62, 1991.

U. S. Department of Labor, Bureau of Labor Statistics. Employment, Hours, and Earnings, States and Areas, 1972 - 1987, volumes I - V. Washington, DC: Government Printing Office, 1989.

U. S. Department of Labor, Bureau of Labor Statistics. Employment and Earnings. v. 38:66- 83, 1991. 